\title{
ESTRATÉGIAS PARA A INSERÇÃO DE MUSEUS DE CIÊNCIAS NO ESTÁGIO SUPERVISIONADO EM ENSINO DE QUÍMICA
}

\author{
Rafael Cava Mori ${ }^{\mathrm{a}, *,{ }^{\circ}}$ e Ana Cláudia Kasseboehmer ${ }^{\mathrm{b}}$ \\ ${ }^{a}$ Centro de Ciências Naturais e Humanas, Universidade Federal do ABC, 09210-580 Santo André - SP, Brasil \\ bDepartamento de Físico-Química, Instituto de Química de São Carlos, Universidade de São Paulo, 13566-590 São Carlos - SP, Brasil
}

Recebido em 10/04/2019; aceito em 10/06/2019; publicado na web em 31/07/2019

\begin{abstract}
STRATEGIES FOR INCLUDING SCIENCE MUSEUMS INTO SUPERVISED CHEMISTRY TEACHER INTERNSHIPS. Considering the importance of non-school educational spaces to diffusing scientific knowledge, as well as arguments for the inclusion of such spaces into initial teacher education, this study presents four strategies to make them practice field institutions in chemistry teacher licensure programs. Assuming that the modalities of the educational phenomenon can be divided into unsystematic and systematized - whether they be school or non-school forms -, the strategies were named as follows: a) Learning (from) the concept of systematicity; b) The school learns from the museum (or the museum learns from the school); c) The museum in the school; and d) Systematizing non-systematic school education. After describing the strategies, we analyzed reports of chemistry teachers in training. These reports included reflections on the social importance of school and chemical knowledge, and they overcame the technical and practical rationalities by incorporating principles of critical rationality.
\end{abstract}

Keywords: teacher training; systematized education; museum; critical rationality.

\section{INTRODUÇÃO}

No Brasil, a formação inicial docente tem passado por transformações nas últimas décadas. A Lei n. $9.394 / 96,{ }^{1}$ ao estabelecer as diretrizes e bases da educação nacional, determinou que tal processo deveria ser conduzido apenas por instituições de educação superior (IES). A progressiva adaptação das IES à nova legislação, na transição para o século XXI, foi orientada por um novo ideário pedagógico. Esse, difundido sob denominações como epistemologia da prática docente ou pedagogia do professor reflexivo, propunha-se a fundamentar a formação docente a partir de bases pragmáticas, e não mais pelos princípios positivistas da racionalidade técnica. ${ }^{2} \mathrm{~A}$ reorganização das matrizes curriculares dos cursos de formação inicial dos professores contribuiu para atenuar o predomínio das licenciaturas do tipo " $3+1$ ", enfraquecer a influência do positivismo e consolidar as ideias de racionalidade prática, oriundas da pedagogia do professor reflexivo. Essas ideias foram bem acolhidas pela comunidade intelectual, propagando-se tanto em documentos oficiais, ${ }^{3-7}$ quanto na produção acadêmica sobre o tema da formação docente. ${ }^{8}$

A formação dos professores brasileiros recebeu novos incentivos na transição entre os anos 2000 e 2010. Destacam-se, na década atual, duas iniciativas do Governo Federal: o Programa Institucional de Bolsas de Iniciação à Docência ${ }^{9}$ e a aprovação das Diretrizes Curriculares Nacionais para a formação inicial em nível superior (cursos de licenciatura, cursos de formação pedagógica para graduados e cursos de segunda licenciatura) e para a formação continuada (Resolução CNE/CP 2/2015). ${ }^{10}$ Essas iniciativas atenderam, parcialmente, a anseios de educadores pela valorização do magistério, garantindo novos recursos financeiros para a formação inicial e contínua de professores e o estabelecimento de um mínimo de 3.200 $\mathrm{h}$ de trabalho acadêmico nas licenciaturas. Especificamente quanto aos estágios curriculares, a Resolução CNE/CP 2/2015 manteve (em relação ao documento análogo anterior, a Resolução CNE/CP

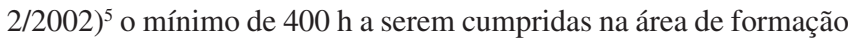
e atuação do licenciando na educação básica, contemplando também

*e-mail: rafael.mori@ufabc.edu.br outras áreas, a depender do projeto de curso da instituição formadora.

Mais recentemente, outras ações vêm sendo propostas na esteira da Política Nacional de Formação de Profissionais da Educação Básica, instituída em 2016, como o Programa de Residência Pedagógica, ${ }^{11}$ além das expectativas diante de uma Base Nacional Comum de Formação Docente.

O debate acadêmico se mantém efervescente e, no campo da formação de professores, a própria racionalidade prática passou a conviver com referenciais focados numa racionalidade crítica. ${ }^{12} \mathrm{~A}$ pedagogia do professor reflexivo, apesar de importante alternativa ao positivismo, mostrou-se insuficiente para formar professores menos alheados a questões mais amplas que interferem em seu trabalho - como a reconfiguração das relações de produção e do trabalho educacional na sociedade pós-moderna, em que emergem novas modalidades de educação conforme se ampliam as possibilidades e os espaços para formar e informar a população.

Emergem, assim, outros modelos para a formação docente, como o sócio-reconstrucionista, o emancipatório ou transgressivo e o ecológico crítico, ${ }^{13}$ além de propostas baseadas em teorias educacionais progressistas, como a pedagogia histórico-crítica. ${ }^{14}$ Ainda que o conjunto desses referenciais represente uma arena prenhe de debates e disputas internas, é possível identificar um núcleo comum de proposições, configurando-os como diferentes expressões da racionalidade crítica. Assim, contrapõem-se aos modelos positivistas, na medida em que consideram a formação docente como um processo que ultrapassa a aquisição de competências e habilidades apenas complementares a saberes científicos específicos. Também, desafiam os modelos calcados no pragmatismo, especialmente, a epistemologia da prática, por não sobrelevarem qualquer polo da práxis, a unidade teórico-prática. Pelo contrário, os modelos críticos, ainda que apreciem os processos reflexivos disparados pelos desafios da prática docente, apostam na proficuidade do estudo aprofundado das teorias pedagógicas, visando formar individualidades menos alienadas. Preocupam-se, assim, com o preparo de docentes enquanto intelectuais inseridos numa realidade objetiva e repleta de contradições, compreendendo a escola como instituição determinada pela sociedade, mas capaz de contribuir para sua transformação. A reflexão docente, assim, deixa de ser apreendida 
como um momento solitário de busca por soluções imediatas. No lugar disso, concebe-se que o ato reflexivo é socialmente mediado: primeiro, porque é iluminado pelas teorias, reconhecendo-as não como produtos emanados de mentes privilegiadas, mas enquanto construtos em constante elaboração coletiva, a partir da dialética homem-realidade; e depois, porque tal ato não deve ser interrompido no psiquismo subjetivo, mas deve se concretizar enquanto ação sobre as estruturas naturais e sociais, posicionando o docente em diálogo (e confronto) com outros sujeitos da comunidade escolar, e mesmo da comunidade científica.

Esse texto, inspirando-se nesses referenciais, tem como objetivo discutir e defender a utilização dos espaços não escolares, como museus/centros de ciências, para a formação dos professores de química. A discussão é desenvolvida em três seções.

A primeira traz aspectos históricos e conceituais referentes a tais espaços, ressaltando-se sua importância para a divulgação e a aprendizagem do conhecimento científico.

A seguir, à luz de uma revisão da literatura, são apresentadas quatro estratégias para tornar museus/centros de ciências instituições-campo nos estágios em química, ao menos quanto ao cumprimento parcial das horas exigidas pela legislação. As estratégias foram propostas considerando-se a importância dos espaços de educação não escolar na sociedade contemporânea, bem como a imprescindibilidade de que as instituições formadoras tematizem e problematizem a missão social desses ambientes e suas especificidades em relação à educação escolar.

Por fim, partindo de uma técnica de análise conteúdo, são investigados cinco relatórios produzidos por licenciandas em química de uma IES pública, que cumpriram horas de estágio conforme as quatro estratégias acima mencionadas.

\section{ESPAÇOS NÃO ESCOLARES NO ENSINO DE QUÍMICA}

A origem dos museus remonta a um hábito recorrente da PréHistória ao Renascimento, tendo Aristóteles (384-322 a.C.) como expoente: a coleção de objetos naturais para fins de estudo. ${ }^{15}$ Mais tarde, a partir de repositórios particulares da nobreza reunidos com fins de ostentação, surgem os chamados gabinetes de curiosidades, que progressivamente se abrem à visitação pública e adquirem uma função educativa, a se consolidar no século XIX..${ }^{16}$ Nesse momento, quando já se utiliza a palavra museu para intitular essas coleções talvez em referência ao ambiente reflexivo do Mouseion de Alexandria (século III a.C.) -, engendra-se a noção de complementaridade entre as tarefas educativas da escola e desses espaços. ${ }^{17}$ No século XX, emerge uma disciplina específica para o estudo dos museus e instituições congêneres (a museologia) e evidenciam-se as especificidades da educação museal frente à educação escolar, diferenciando-se a atuação dessas entidades entre exposições propriamente ditas (lidando com objetos expositivos cada vez menos sacralizados, até o ponto da virtualização, nos dias atuais) e as chamadas ações educativas. ${ }^{18}$

A nomenclatura empregada para se referir ao caráter educacional de museus e instituições correlatas é objeto de contendas. Os países anglófonos costumam se referir a museus como instituições de educação informal; já os países lusófonos empregam o termo não formal. ${ }^{19}$ As tipologias, ainda, se orientam conforme diferentes critérios, ${ }^{20}$ havendo autores que problematizam a demarcação rígida entre os contextos educacionais formal e não formal/informal. ${ }^{21}$

A tipologia de Mori e Curvelo ${ }^{22}$ sugere situar as modalidades de educação no contínuo entre as formas assistemática e sistematizada, podendo ser também escolares ou não escolares (Figura 1).

Essas categorias baseiam-se no pensamento de Dermeval Saviani, que considera a escola a principal forma institucionalizada de educação, daí ela ser tomada como parâmetro, tratando-se demais instituições educadoras como não escolares. ${ }^{23}$ Além disso, esse autor diferencia as formas sistematizadas das formas assistemáticas de educação, entendendo que as primeiras se organizam enquanto práxis que atendem aos seguintes requisitos: 1) tomam consciência da situação (estrutura) que requer um trabalho educacional; 2) captam os problemas dessa situação; 3) refletem sobre eles; 4) formulam-nos em termos de objetivos realizáveis; 5) organizam meios para alcançar tais objetivos; 6) instauram processos concretos que os realizam; e 7) mantêm ininterrupto o movimento dialético ação-reflexão-ação, retornando ao requisito 1). ${ }^{24}$ Considerando, portanto, as dimensões assistemática/sistematizada e escolar/não escolar, revelam-se quatro modalidades de fenômenos educativos: a) educação escolar sistematizada - coincide com o que se considera como educação formal; b) educação escolar assistemática - refere-se às aprendizagens que ocorrem na escola, mas de forma incidental, não planejada, aproximando-se do conceito de currículo oculto $;^{25} \mathrm{c}$ ) educação não escolar assistemática - abrange a educação resultante da mera convivência e da exposição a produtos e artefatos culturais, fora dos espaços escolares; e d) educação não escolar sistematizada - compreende os cursos de frequência facultativa (por exemplo, de idiomas) e processos educativos sediados em instituições diversas, como museus/centros de ciências.

É verdade que o ensino de química, atualmente, está concentrado no quadrante referente à educação escolar sistematizada. No entanto, representando a educação não escolar sistematizada, algumas instituições brasileiras vêm contribuindo para comunicar o conhecimento químico a amplas audiências. O Guia de centros e museus de ciência do Brasil $2015^{26}$ lista 268 dessas instituições, das quais $40 \%$ oferecem alguma atividade relacionada ao universo da

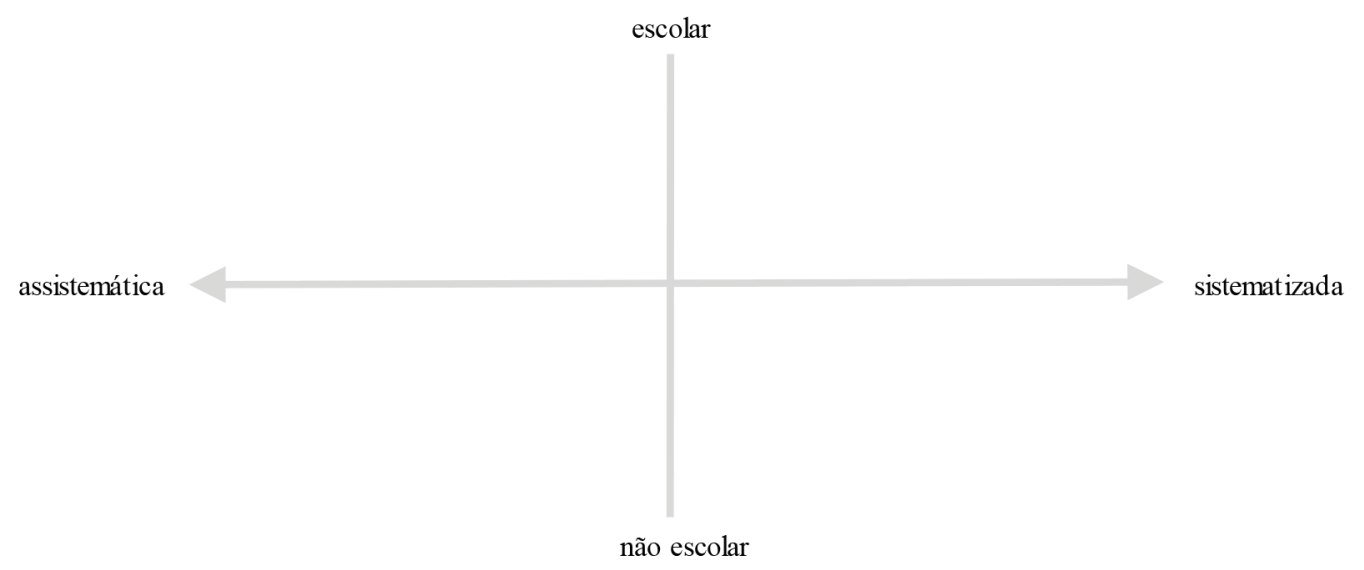

Figura 1. Modalidades de educação entre as dimensões assistemática/sistematizada e escolar/não escolar. Extraído da ref. 22 (p. 501) 
química, segundo o levantamento de Steola e Kasseboehmer. ${ }^{27}$ As autoras identificaram ainda que tais atividades, geralmente, abrangem ações educativas de apoio às escolas ou à formação docente, havendo poucas exposições com temas químicos. Palmieri e Silva, ${ }^{28}$ numa revisão bibliográfica, encontraram resultados semelhantes. Além de diagnosticar a escassez de trabalhos científicos sobre as relações entre museus/centros de ciências e educação em química, as autoras identificaram apenas cinco instituições cujas iniciativas foram objeto dessa literatura nas últimas duas décadas: o Museu de Astronomia e Ciências Afins (MAST)/RJ, o Museu da Vida/RJ, o Centro de Ciências de Araraquara/SP, o Museu Nacional/RJ e o Museu da Geodiversidade/RJ.

Para o conjunto de autoras mencionadas no parágrafo acima, a química deveria merecer maior atenção por parte dos agentes e dos estudiosos do campo da museologia no Brasil. Ao que parece, esses sujeitos vêm manifestando um entendimento restrito ou incompleto sobre essa ciência, reduzido a seu caráter experimental, o que limitaria o planejamento e a execução de exposições, por conta de fatores como a necessidade de reposição/descarte de reagentes/produtos químicos. No entanto, é sim possível conceber materiais expositivos focados no conhecimento da química e isentos das dificuldades relacionadas aos procedimentos dessa ciência, como atesta o exemplo do Centro de Ciências da Universidade Federal de Juiz de Fora, propondo uma exposição que conjuga objetos virtuais e reais numa Tabela periódica interativa. ${ }^{29}$

Outrossim, como apresentado adiante, há exposições que mesmo não planejadas precipuamente para a divulgação da química, servem a isso. Nelas, não se enfatizam aspectos procedimentais, mas outras questões também relevantes para a aprendizagem do conhecimento químico.

\section{ESPAÇOS NÃO ESCOLARES NA FORMAÇÃO DE PROFESSORES DE QUÍMICA}

Abib e colaboradores,${ }^{30}$ revisando a literatura que abordou simultaneamente os assuntos "formação docente" e "espaços não formais" em periódicos nacionais sobre o ensino de ciências, observaram a média próxima a um artigo publicado por ano no período 2001-2011. Prevaleceram estudos sobre formação contínua de professores e a inicial foi tematizada em apenas três produções.

De fato, museus/centros de ciências têm participação tímida nas licenciaturas brasileiras. Relatam-se algumas articulações, carentes de maior sistematicidade, entre disciplinas de prática de ensino, a prática como componente curricular e matérias específicas que abordam tais espaços. ${ }^{31}$

No entanto, a defesa pela inserção dos ambientes não escolares nas licenciaturas em ciências, enquanto geradores de novos espaços-tempos formativos, remonta a pelo menos o início do século na literatura brasileira ${ }^{32}$ e a uma década antes no contexto português. ${ }^{33} \mathrm{O}$ tema permaneceu abordado na produção acadêmica dos últimos anos, observando-se sua divisão em duas frentes: estudos sobre a formação de mediadores em exposições de ciências, dada a ausência de espaços próprios para sediar esse processo; e trabalhos que relatam e analisam experiências de inclusão, curricular ou extracurricular, de espaços não escolares nas licenciaturas. Frequentemente, essas frentes se intersectam, já que museus/ centros de ciências ligados a universidades recrutam licenciandos como mediadores, enquanto bolsistas ou voluntários em atividades acadêmico-científico-culturais.

Esses trabalhos reconhecem as especificidades dos museus/ centros de ciências frente à educação escolar, endossando Queiroz e colaboradores ${ }^{34}$ que identificam a existência de saberes que os espaços não escolares compartilham com a escola, saberes específicos da educação científica também compartilhados por ambas as instituições e saberes característicos da mediação museal.

Alguns argumentos pela maior presença de espaços não escolares na formação docente são:

- A atuação em museus/centros de ciências, com seus públicos abrangentes, prepara os professores para situações escolares que requerem imaginação e criatividade, aprimorando seus saberes de mediação, ${ }^{35}$

- Os docentes ficam mais aptos e dispostos a incorporar visitas extraescolares ao ensino, visando articular aprendizagens nos museus com saberes escolares; ${ }^{36}$

- O contato com objetos e ações museais enriquece os próprios saberes sobre conteúdos específicos (por exemplo, conhecimentos químicos, físicos ou biológicos), além dos saberes pedagógicos dos professores em formação; ${ }^{37}$

- Incentiva-se o hábito, por parte dos educadores, a frequentarem museus e demais "casas da cultura", ampliando sua erudição científica. $^{31}$

Acrescentam-se a esses argumentos a possibilidade de as interatividades próprias dos museus - dos tipos hands on (manual/corporal), minds on (mental/cognitiva) e hearts on (cultural/afetiva) - ${ }^{38}$ inspirarem atividades escolares também mais interativas. É possível, além disso, o aprimoramento do conceito de transposição didática pelo licenciando, pelo cotejamento com seu equivalente no campo museal, a transposição museográfica. ${ }^{39}$ Isso repercutiria na habilidade do docente em didatizar conteúdos escolares e em portar-se como autor de saberes próprios da escola, considerando que essa instituição não é mero receptáculo de "saberes sábios" oriundos da academia.

Especificamente quanto ao ensino de química, há propostas para inserir espaços não escolares nas licenciaturas, ${ }^{29,40,41}$ mas são esforços isolados. Gonçalves e Fernandes, em publicação de 2010, ${ }^{42}$ mas cujos resultados parecem permanecer atuais, observaram que licenciandos e formadores não reconhecem outros ambientes, que não a sala de aula, como relevantes para a formação e a atuação docente. Para os autores, o estágio supervisionado em ensino de química poderia abranger essas vivências extraescolares, em espaços como os museus, hospitais e ONGs.

Essa carência de intentos mais sistematizados sobre a participação de ambientes não escolares no estágio em ensino de química é o que motiva a compartilhar e analisar as estratégias a seguir. Por sua vez, elas buscaram superar uma dificuldade específica da IES que sediou sua implementação, que divide temporalmente o ano acadêmico em três períodos (quadrimestres). Isso traz limitações para estagiários do segundo período do ano, iniciado no começo de junho e concluído ao final de agosto, abrangendo o recesso escolar de julho e dificultando, portanto, o cumprimento do total horas de estágio em salas de aula da educação básica. Pelos argumentos desenvolvidos acima, mesmo instituições com outros arranjos curriculares, possibilitando dispor a carga horária de estágio integralmente em espaços escolares, podem considerar os museus de ciências como espaços formativos importantes para os futuros professores.

Clássicos sobre a prática de ensino de ciências, como a obra de Krasilchik, ${ }^{43}$ distinguem três grupos de estágios: de observação, de participação e de regência. Esta proposta foi dividida em duas modalidades: os estágios predominantemente de observação e os predominantemente de intervenção (estes abrangem, portanto, a participação e a regência). Subjaz a tal rotulação o conceito de contínuo participante-observador, como definido na literatura sobre pesquisa qualitativa em educação. Num dos extremos, está o observador completo, que não atua nas atividades do campo de estágio e, no outro, o investigador totalmente envolvido com a instituição em que estagia. Como afirmam Bogdan e Biklen, os investigadores de campo situamse algures entre esses dois polos. ${ }^{44}$ Além disso, considera-se que a 
mera presença do observador já interfere na situação observada e que mesmo projetos de intervenção dependem, em alguma medida, de observações prévias. ${ }^{45}$ Assim, a proposta se inspira na concepção de estágio com pesquisa, envolvendo coletas de dados nas instituições-campo e diálogos com a literatura educacional. Essa perspectiva, para Pimenta e Lima, ${ }^{46}$ tende a substituir o modelo tradicional de observação/participação/regência e aponta para a configuração do estágio como área de conhecimento.

Tomando como referência o diagrama da Figura 1, as quatro estratégias são apresentadas a seguir, sendo nomeadas conforme seus objetivos gerais. Todas dividem o cumprimento de horas de estágio entre espaços escolares e não escolares. Assim, espera-se que os licenciandos, por meio dessas estratégias, estagiem em ao menos duas modalidades de espaços educativos, dentre as quatro dispostas na Figura 1. Ainda, para cada estratégia estão antecipados os resultados para os dois tipos de estágio, o predominantemente de observação e o predominantemente de intervenção. Nos diagramas que ilustram as quatro propostas, esses tipos estão identificados com as cores verde e vermelho, respectivamente, reservando-se a cor azul para identificar $\mathrm{a}(\mathrm{s})$ atividade(s) resultantes(s) do estágio predominantemente de intervenção. As quatro estratégias propostas são:

a) Aprendendo (com) o conceito de sistematicidade (Figura 2): o estagiário transita por diferentes espaços, começando pela sala de aula, passando pelo museu/centro de ciências (ou outro espaço de educação não escolar sistematizada) e terminando num espaço de educação não escolar assistemática. O conjunto dessas vivências deve conduzir a uma reflexão sobre as especificidades desses locais, considerando seus limites e possibilidades para o ensino de química. Nesse percurso, aprimora-se o conceito de sistematicidade da prática educativa, conforme as observações tomadas nos três tipos de ambiente. O estágio predominantemente de intervenção, para além disso, deve capacitar o docente em formação a integrar elementos do espaço de educação não escolar assistemática à sua práxis educativa, alçando tal espaço a um sítio para a atuação sistematizada - por exemplo, planejando ou executando uma exposição ou ação educativa nesse local.

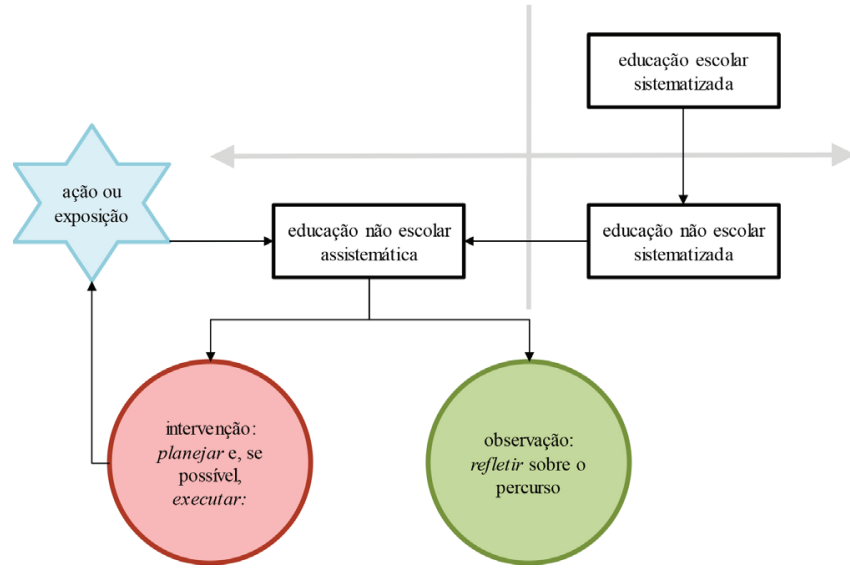

Figura 2. Diagrama ilustrativo da estratégia a) Aprendendo (com) o conceito de sistematicidade

b) A escola aprende com o museu (ou o museu aprende com a escola) (Figura 3): essa estratégia está mais adaptada aos estágios que tomam como tema as atividades experimentais. Com efeito, existem museus/centros de ciências que proporcionam demonstrações na forma de "shows de química". Um estágio interessado nessa questão poderia partir das possibilidades para a experimentação no espaço escolar, com foco em atividades que releguem maior autonomia aos estudantes, para depois se analisar a atividade demonstrativa no museu. Enquanto o estágio predominantemente de observação pode ser concluído com reflexões sobre a experimentação diante dos contextos escolar e não escolar, o estágio predominantemente de intervenção deve gerar como produtos: ou a proposta de uma regência envolvendo uma demonstração motivadora na própria escola; ou um projeto para atividades mais abertas e investigativas, a ser comunicado à instituição museal, visando ao aprimoramento de suas demonstrações, se possível.

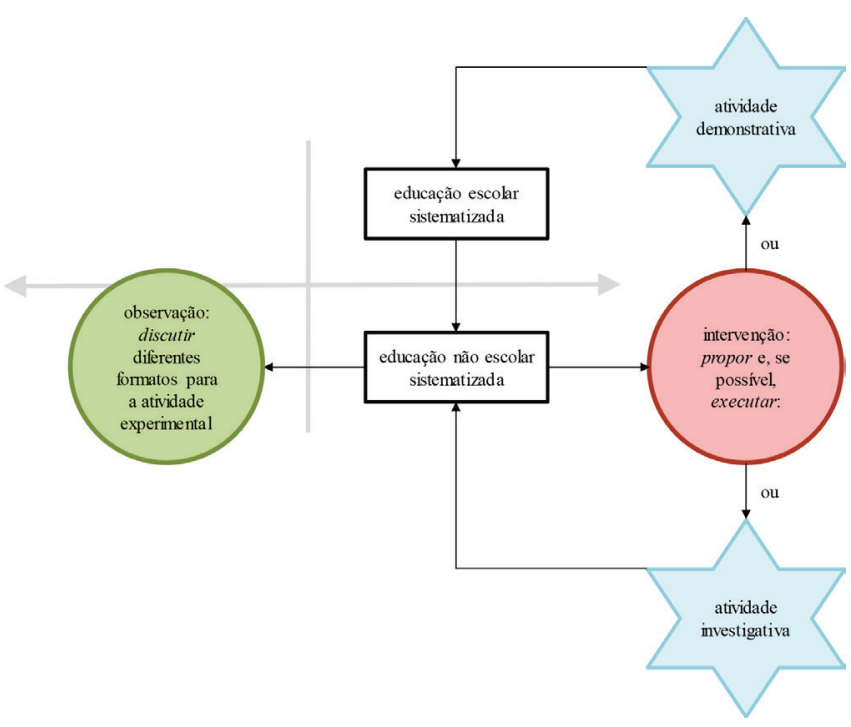

Figura 3. Diagrama ilustrativo da estratégia (b): A escola aprende com o museu (oи o museu aprende com a escola)

c) O museu na escola (Figura 4): algumas escolas possuem objetos que poderiam ser expostos, como aparatos e vidrarias de caráter histórico ou antigas produções estudantis (por exemplo, modelos de bola e vareta feitos com isopor e palitos), jazendo no laboratório ou outro espaço. As escolas em que isso ocorre oportunizam a presente estratégia, inspirada no trabalho de Zancul. ${ }^{47}$ Assim, após um período de observações e levantamentos desses materiais no espaço escolar, o licenciando visita um ou mais museus/centros de ciências, visando compreender ou se apropriar dos saberes museais que permeiam a concepção de uma exposição de ciências. No estágio predominantemente de observação, reflete-se sobre como elementos com potencial expositivo, presentes na escola, poderiam ser dispostos para o ensino de química. Já no estágio predominantemente de intervenção espera-se, além dessas reflexões, a elaboração de um projeto para essa exposição escolar, acompanhado de um plano de ensino que contemple sua visita por parte dos alunos. É desejável que o estagiário retorne à escola e execute o projeto e o plano enquanto atividade de regência.

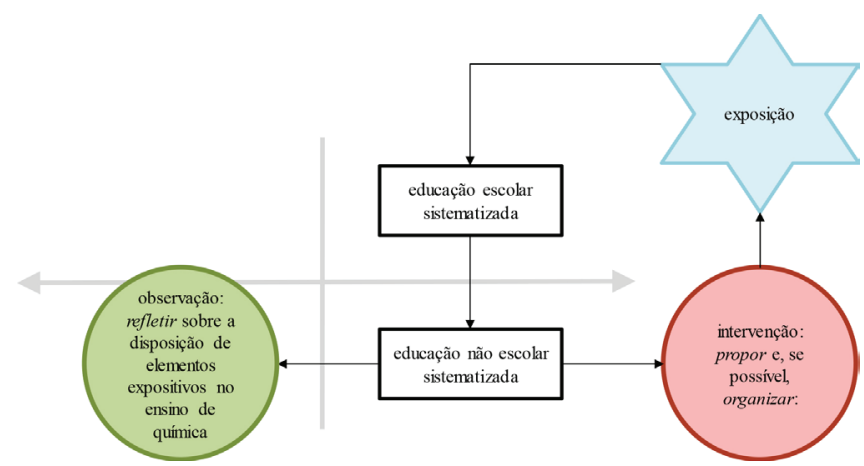

Figura 4. Diagrama ilustrativo da estratégia (c) O museu na escola 
d) Sistematizando a educação escolar assistemática (Figura 5): nos dias que antecedem períodos de recesso, a presença discente às aulas costuma diminuir. Então, muitas escolas adotam programações com atividades extraclasse não previstas nos planejamentos. Esta quarta estratégia incide sobre esse fato. Após o estágio no espaço da sala de aula propriamente dito, o licenciando pode vir a presenciar essas atividades escolares improvisadas e assistemáticas. Seu contraste com a educação sistematizada é realçado pelo estágio subsequente em ambientes não escolares - passando-se, por exemplo, de museus/centros de ciências a outros locais não intencionalmente preparados para sediar o ensino de química. Assim, após completar o percurso pelos quadrantes da Figura 1, o estagiário pode refletir sobre a valorização das formas mais sistematizadas de educação, especialmente no espaço escolar. Caso realize o estágio predominantemente de intervenção, espera-se que proponha atividades, voltadas para o ensino de química, que ocupem o espaço da educação escolar assistemática, privilegiada nas temporadas de esvaziamento da escola. O produto desse estágio contribuiria para apor maior sistematicidade a atividades escolares que desperdiçam tempo e recursos, os quais deveriam cooperar para a tarefa precípua da escola: transmitir o conhecimento às novas gerações. ${ }^{48}$

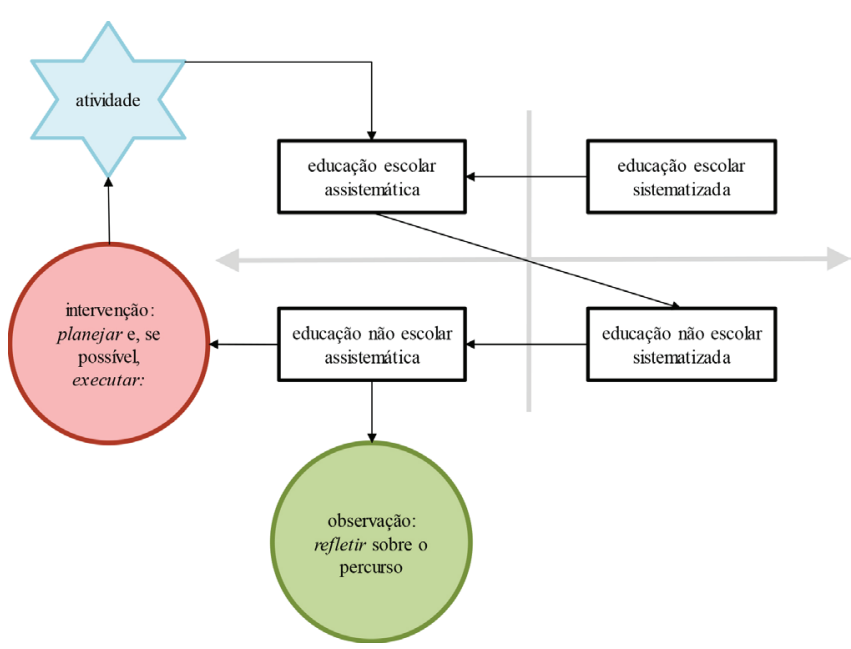

Figura 5. Diagrama ilustrativo da estratégia d) sistematizando a educação escolar assistemática

\section{A EXPERIÊNCIA DO ESTÁGIO EM ESPAÇOS NÃO ESCOLARES: UMA ANÁLISE}

A seguir, será feita uma breve análise de como essas quatro estratégias foram postas em marcha na IES a que pertence um dos autores deste texto, que atuou como orientador de estágio.

No currículo da Licenciatura em Química dessa IES, o cumprimento das 400 h de estágio está dividido em cinco módulos de 80 h: três deles para o componente curricular Química do ensino médio $(240 \mathrm{~h})$ e dois para o componente Ciências do ensino fundamental (160 h). Assim, visando cumprir 80 h de estágio em Química, cinco licenciandas se matricularam no módulo em que a experiência ocorreu; três delas realizaram o estágio predominantemente de observação, e as demais, o estágio predominantemente de intervenção. Essa distinção se deveu aos diferentes coeficientes de progressão das estudantes em seu curso de licenciatura, já que os módulos de estágio, na IES em questão, admitem matrículas, numa mesma turma, de quaisquer graduandos, estejam eles mais próximos do ingresso ou da conclusão do curso.

A experiência ocorreu no $2^{\circ}$ quadrimestre de 2017, entre a última semana de maio e a terceira de agosto - abrangendo, portanto, o recesso escolar de julho. As licenciandas, iniciando seus estágios em diferentes escolas, enfrentaram variados graus de dificuldade quanto ao cumprimento de horas em espaços escolares. Assim, cada licencianda escolheu uma das quatro estratégias (sendo que uma das estratégias foi adotada por duas licenciandas), considerando sua adequação à realidade das escolas-campo e discussões nas reuniões de orientação. O percentual de horas em espaços não escolares variou de 19 a $26 \%$ do total de $80 \mathrm{~h}$, conforme a estagiária, perfazendo a média de $20 \%$ (16 h). Foram visitados dez espaços não escolares: a licencianda que mais fez visitas esteve presente em todos eles; já a licencianda que menos saiu a campo visitou apenas dois.

O conjunto dessas informações é sumarizado na Tabela 1, que também apresenta a relação dos espaços não escolares visitados pelas estagiárias. Esses espaços estão distribuídos pelos municípios paulistas de Santo André, São Bernardo do Campo, São Caetano do Sul e São Paulo.

Ainda, a experiência foi regida pelas seguintes orientações.

A primeira concerne à perspectiva do estágio com pesquisa, o que direcionou as estagiárias a escolherem, livremente, temas da educação em química a serem investigados no cumprimento das $80 \mathrm{~h}$. De forma a orientar as coletas de dados, além de incentivar o exercício reflexivo e o processo de tornar as estagiárias autoras de seu processo de formação, o orientador de estágio distribuiu a elas cadernos, que seriam seus diários de pesquisa. A produção dos diários buscou superar a perspectiva da escrita subjetivista, por dois motivos: primeiro, porque os registros acompanhavam as reuniões de orientação de estágio, sendo alimentados pelas discussões grupais que ali aconteciam; e depois, porque as anotações das licenciandas poderiam ser requeridas, a qualquer momento, pelo orientador. Em outra mão, esse também elaborou seu próprio diário de pesquisa, na forma de um blog com postagens semanais. ${ }^{49}$ Assim, os registros foram guiados pelo princípio da reciprocidade (inspirando-se na

Tabela 1. Especificações dos relatórios analisados

\begin{tabular}{lcccc}
\hline Relatório & Estágio* & $\begin{array}{c}\text { Horas em espaços não } \\
\text { escolares (\%) }\end{array}$ & Estratégia & Espaços visitados \\
\hline 1 & $26 \%$ & d & ESC, CAT, BUF, GEO, PRC \\
2 & $19 \%$ & c & ESC, CAT, GEO, IBB, IBM, IBH, BIB, BUF, BMA, BRU, PRC \\
3 & observação & $20 \%$ & a & ESC, CAT, GEO, BUF, PRC \\
\hline 4 & $15 \%$ & b & ESC, CAT, PRC \\
5 & intervenção & $21 \%$ & a & ESC, GEO, IBB, PRC \\
\hline
\end{tabular}

*Predominantemente. Legenda: ESC - escolas; CAT - Catavento Cultural; GEO - Museu do Instituto de Geociências (IGc-USP); PRC - Parque Regional da Criança "Palhaço Estremilique"; IBB - Museu Biológico do Instituto Butantan; IBM - Museu de Microbiologia do Instituto Butantan; IBH - Museu Histórico do Instituto Butantan; BIB - Biblioteca do Instituto Butantan; BMA - Biblioteca Mário de Andrade; BUF - Biblioteca da Universidade Federal do ABC; BRU - Coordenadoria Geral de Bibliotecas da Universidade Estadual Paulista "Júlio de Mesquita Filho". 
fala de Remi Hess em entrevista a Barbosa, na obra $O$ diário de pesquisa: o estudante universitário e seu processo formativo),,$^{50} \mathrm{em}$ que orientador e licenciandas concordaram em compartilhar entre si suas produções escritas. Apesar dessa prerrogativa, os diários das estagiárias não foram requeridos para o visto do orientador.

A segunda orientação se relaciona com o seguinte fato: a experiência envolveu a imersão também do orientador nos espaços de estágio, que esteve em campo junto das licenciandas, exceto nos espaços escolares. As visitas aos espaços não escolares foram conduzidas geralmente com grupos de três estagiárias, pois as licenciandas possuíam diferentes agendas e ocupações. Já as reuniões de orientação envolviam todo o grupo.

Ao final da experiência, cada licencianda entregou um relatório escrito. Os relatórios apresentaram cada um, em média, 10 referências e 4.364 palavras (para efeitos de comparação, o blog do professor-orientador sediou 10 postagens sobre os estágios, totalizando 9.131 palavras).

O exame dos relatórios, neste trabalho, partiu do tratamento do corpus para a aplicação da técnica de análise de coocorrências, por meio do software IRAMUTEQ ${ }^{\mathrm{TM}}$ (Interface de R pour les Analyses Multidimensionnelles de Textes et de Questionnaires), visando identificar relações de contingência (associação/dissociação) de unidades de análise numa mesma unidade contexto. As unidades de análise foram verbos, substantivos e adjetivos, em contextos delimitados como segmentos de texto com 40 palavras. A análise de coocorrências foi escolhida por sua pertinência em avaliar a experiência de estagiar em contextos diversos; por exemplo, a coocorrência de unidades de análise relativas aos museus/centros de ciências e unidades relativas ao contexto escolar (ou à educação de forma mais ampla) fortaleceria a hipótese de que os diferentes espaços foram de fato integrados no processo formativo das licenciandas, no lugar de se constituíram como loci isolados. Tal integração, nesse exemplo, indicaria uma atitude influenciada pelos princípios da racionalidade crítica, por denotar maior consciência de que os diferentes espaços educacionais, apesar de suas especificidades, compartilham de uma mesma finalidade social relativa ao conhecimento científico. Nesse sentido, o emprego de um software se mostrou fundamental, sendo inclusive recomendado por uma das principais especialistas em técnicas de análise de conteúdo, Laurence Bardin, que afirma ser interessante recorrer ao computador quando "deseja-se efetuar uma análise de coocorrências (aparição de duas ou várias unidades de registro numa mesma unidade de contingência" (p.175). ${ }^{51}$

A análise, assim, agrupou os conteúdos dos relatórios em cinco clusters, cujos principais termos coocorrentes estão apresentados na Tabela 2.

Ainda, constataram-se as seguintes relações de contiguidade (entre aspas, os termos coocorrentes):

- Para o conjunto dos relatórios, a palavra "aluno" foi central, coocorrendo com "aprendizagem" e "conteúdo". Tais relações evidenciam a consciência das licenciandas frente aos objetivos educacionais específicos da escola;

- A "escola" ou ("espaço escolar") apareceu como instância mediadora entre o "conhecimento" e o "aluno", sugerindo que as docentes em formação compreendem a escolarização enquanto etapa para a socialização dos indivíduos na cultura elaborada;

- Ainda, as menções a "espaços" como o "museu" e a "biblioteca" foram coocorrentes com a "escola", o que demonstra um entendimento de que, para as estagiárias, a educação escolar é a referência a partir da qual outros ambientes educativos possam ser aproveitados para a apropriação do saber pelas novas gerações;

- O próprio "estágio" foi um termo coocorrente com os termos "universidade", "ensino", "observar" e "pensar", indicando a noção de que o curso de licenciatura deva promover reflexões que,
Tabela 2. Resultado da análise de coocorrências, aplicada aos relatórios das licenciandas

\begin{tabular}{ll}
\hline cluster* $^{*}$ & principais termos coocorrentes (ordem alfabética) \\
\hline a prática educativa & $\begin{array}{l}\text { ambiente, conhecimento, diferente, escolar, espaço, } \\
\text { ocorrer, parque, sistematizar, utilizar, visitar }\end{array}$ \\
\hline $\begin{array}{l}\text { aluno, apresentar, atividade, aula, avaliação, escolar, } \\
\text { forma, laboratório, livro, material, observação, pesqui- } \\
\text { sa, possibilidade, possível, possuir, prático, processo, } \\
\text { professor, realizar, relação, sala, trabalho }\end{array}$ \\
\hline o museu & ciência, exposição, museu, visita \\
\hline a biblioteca & $\begin{array}{l}\text { acervo, biblioteca, informação, interação, local, mo- } \\
\text { mento, objeto, público }\end{array}$ \\
\hline a universidade & ensino, estágio, observar, pensar, químico, universidade \\
\hline *O título de cada cluster foi proposto pelos autores deste texto.
\end{tabular}

futuramente, irão orientar o trabalho educativo do profissional formado.

Essas considerações gerais podem ser ilustradas com excertos dos próprios relatórios.

O relatório 1, sobre um estágio do tipo d) Sistematizando a educação escolar assistemática, partiu da crítica de Saviani sobre a confusão entre atividades curriculares e extracurriculares no interior da escola, ${ }^{23}$ considerando que " a situação vivida na escola nesse estágio se enquadra nessa descaracterização do trabalho escolar, onde a possibilidade de inversão de saberes não disponíveis em outros lugares é substituída por mais uma oportunidade de demostrar a cultura já inserida na vida desses alunos". À luz da visita a espaços como o Catavento Cultural e o Museu do Instituto de Geociências, a estagiária refletiu sobre seu percurso por diversas modalidades do fenômeno educativo e se posicionou pela sistematização das experiências escolares assistemáticas. Tendo observado que a semana anterior ao recesso escolar sediou apenas uma "gincana cultural" na escola - com teor mais recreativo e socializador do que educacional -, a docente em formação propôs que esse momento poderia ser aproveitado para atividades direcionadas ao ensino de ciências, ainda que lúdicas. Sua proposta se fundamentou em trabalhos sobre gincanas químicas, encontrados nos anais do Encontro Nacional de Ensino de Química e de outros eventos. ${ }^{52}$

Já o relatório 2 descreveu uma experiência que se apropriou livremente da estratégia c) $O$ museu na escola. A licencianda, já tendo frequentado (no âmbito do Pibid) a escola em que iniciou seu estágio, observou que a biblioteca escolar era pouco usufruída pelos estudantes, que recorriam à internet para elaborar trabalhos de pesquisa - problema comum à maioria das bibliotecas escolares brasileiras, segundo referência citada pela estagiária. ${ }^{53}$ Assim, seu estágio sediou reflexões sobre como viabilizar esse espaço enquanto local para visitação constante e aproximação para com o saber sistematizado, principalmente no âmbito da química. Apesar de ter visitado museus/centros de ciências com as demais licenciandas, a autora do relatório 2 cumpriu grande parte de suas horas de estágio em outras bibliotecas, contemplando a tipologia apresentada no trabalho de Milanesi, ${ }^{54}$ que as discrimina entre as escolares, universitárias, públicas e especializadas. Enquanto que a visita à biblioteca especializada do Instituto Butantan mostrou como esse espaço pode se assemelhar à concepção tradicional do Mouseion, com objetos sacralizados e quase intocáveis, as demais visitas apontaram para visões mais contemporâneas nas áreas de biblioteconomia e ciência da informação. Essas visitas à biblioteca pública (Biblioteca Mário de Andrade) e às bibliotecas universitárias (Biblioteca da Universidade Federal do ABC e Coordenadoria Geral de Bibliotecas da Universidade Estadual Paulista "Júlio de Mesquita Filho", locais 
onde foram realizadas entrevistas semiestruturadas com profissionais que ali trabalham) evidenciaram que elas se assemelham aos atuais museus interativos. No lugar da salvaguarda de acervos, procuram atrair o público de visitantes, facilitando a circulação da informação. Nas palavras da estagiária, "a biblioteca não é apenas um espaço para o armazenamento do acervo recebido, mas um ambiente de educação, desenvolvimento de conhecimento e ação cultural, tanto para a escola quanto para a comunidade externa. [...] Os que visionam a biblioteca contemporânea não mais veem o espaço apenas como uma fonte de informação, mas como um ambiente de intervenção cultural e social." Assim como a autora do relatório 1 propôs que a escola não desperdiçasse oportunidades para garantir aos estudantes o acesso à cultura, a do relatório 2 considerou que a biblioteca escolar poderia atuar como uma extensão - dinamizada, animada, efervescente - da sala de aula: "Durante todo o tempo que se passou pelo estágio, foi ponderado sobre o papel do ensino de química na biblioteca, algo que no primeiro momento parecia uma relação impossível, considerando que tradicionalmente o conteúdo químico é pouco relacionado com a literatura [...]. Com as visitas que ocorreram durante o período de observação e as reflexões com o professor orientador, foi possível concluir que a química pode interferir na biblioteca e torná-la uma extensão da sala de aula [...]." No relatório propõe-se, inclusive, uma atividade que facilitaria a aproximação entre aula de química e biblioteca escolar, inspirando-se num dos espaços visitados durante o estágio: "a professora de química poderia fundar um repositório com todas as atividades que seus alunos fizeram durante o ano, que seriam avaliadas, corrigidas e documentadas, podendo ser utilizadas por novos alunos em anos seguintes, numa 'revista científica' da própria escola".

O relatório 3 abordou o tema da avaliação no ensino de química, conforme a estratégia a) Aprendendo (com) o conceito de sistematicidade. A partir da tipologia de Zabala, ${ }^{55}$ que classifica os conteúdos escolares entre factuais, conceituais e de princípios, procedimentais e atitudinais, a estagiária observou quais deles poderiam ser mais facilmente eliciados em diferentes ambientes (na própria escola, nos museus/centros de ciências e num espaço de educação não escolar assistemática, o Parque Regional da Criança). A licencianda, assim, realizou descobertas que a auxiliaram a elaborar seu próprio conceito sobre avaliação dos conteúdos de química: "Os conteúdos procedimentais e atitudinais são mais raros na avaliação no ambiente escolar, notando o foco no atitudinal apenas para alunos com baixo rendimento durante o Conselho de Classe. [...]. Os espaços não formais de educação sistematizada, como museus e bibliotecas, permitem que esses conteúdos, atitudinais e procedimentais, sejam mais evidentes e com grande potencial de análise, desde que traçados objetivos no plano de visita". As conclusões do relatório apontam para um entendimento crítico sobre como articular as especificidades das formas de educação escolar e não escolar, considerando a necessidade de transmissão do legado da humanidade às novas gerações: "A integração do ambiente escolar com o de museus e bibliotecas é desejável, possibilitando diferentes formas de se apresentar o conhecimento científico, e ampliando o arcabouço cultural dos alunos."

Os relatórios 1, 2 e 3 trouxeram vivências analisadas à luz de disciplinas já cursadas pelas estagiárias no curso de licenciatura, respectivamente, Práticas de Ensino de Química, Livros Didáticos no Ensino de Química e Avaliação no Ensino de Química. Da mesma forma, o relatório 4 envolveu o tema das atividades experimentais, fazendo referência à disciplina Experimentação e Ensino de Química. Assim, esse relatório envolveu a estratégia b) A escola aprende com o museu, em que a licencianda, após analisar uma demonstração experimental oferecida pelo Catavento Cultural, refletiu sobre como aprimorar seus saberes de mediação na educação escolar. Nas palavras da autora, "A aula experimental, em especial, ficou marcada no sentido de que um professor pode ter uma abordagem cativante, e fazer com que os alunos sejam mais participativos. [...] Mas as aulas em sala de aula também podem ser assim; os alunos devem sentir a disposição em participar, e o professor deve ser acolhedor e envolvente a abordar os conteúdos". Ainda, seu relato demonstra preocupação quanto a operacionalizar as aulas experimentais na escola, por conta do comportamento dos alunos, mas considera que os museus/centros de ciências podem colaborar até para essa finalidade: "Uma ambientação para a situação favoreceria um melhor comportamento dos alunos, e também certa regularidade na visitação a outros espaços poderiam fazer com que eles fossem mais participativos e ansiassem para a próxima ida ao laboratório."

Por fim, o relatório 5 também narrou a vivência da estratégia a) Aprendendo (com) o conceito de sistematicidade. De fato, as experiências em campo conduziram a licencianda a entender a importância do trabalho educativo sistematizado: "Ao comparar os espaços visitados - que foram os institutos Butantan e de Geociências, além do Parque da Criança-, percebi que os museus são espaços privilegiados para o ensino. Neles consegui visualizar com uma maior facilidade quais poderiam ser os temas abordados, mesmo que esses temas não fossem relacionados com a química (em um primeiro momento). Já no parque essas relações não foram nada fáceis." Em especial, o Museu de Geociências se mostrou mais marcante para a autora, que elaborou uma atividade de regência, na escola, envolvendo a visitação a esse espaço expositivo, com foco num conteúdo específico: "Após a visita ao Instituto de Geociências, e após lembrar da minha experiência com os alunos sobre as confusões em relação ao conteúdo de ligações químicas, comecei a pensar em uma atividade. Nela, buscaria proporcionar que os alunos, ao irem no museu, não ficassem dispersos, ao mesmo tempo em que pudessem aproveitar um pouco da liberdade que o museu proporciona (já que eles podem conversar e andar livremente enquanto observam os objetos do local)".

Considerando a necessidade de superação das racionalidades técnica e prática, pode-se afirmar que as experiências acima incorporaram diversos princípios da racionalidade crítica no âmbito da formação inicial docente. Os relatórios trouxeram reflexões sobre a importância social da escola e do conhecimento, suplantando as visões, por vezes, fragmentadas e solipsistas da epistemologia da prática. ${ }^{13}$ Ainda, os textos apresentaram indícios de que os estágios contribuíram para a passagem do individualismo à individualidade, isso é, para a construção de personalidades desalienadas e, assim, mais aptas para o exercício da docência. ${ }^{14}$ Por fim, destaca-se a importância da perspectiva do estágio com pesquisa, que proporcionou às licenciandas conhecer e praticar (isto é, colocar à prova) ${ }^{46}$ referenciais teóricos e conteúdos já estudados em outros espaços e tempos do curso de licenciatura - tornando-as, assim, consumidoras e produtoras de pesquisas do campo educacional, ${ }^{56}$ aspecto valorizado pelos princípios da racionalidade crítica.

\section{CONCLUSÕES}

Neste texto, foram apresentadas quatro estratégias para a inserção de espaços não escolares no estágio supervisionado em ensino de química. Argumentou-se pela pertinência da integração desses ambientes na formação de docentes mais críticos e conscientes de diversas questões postas na atualidade - como a educação enquanto assunto público e direito do cidadão, a valorização do conhecimento científico e o reconhecimento da missão social da universidade. Os relatórios das licenciandas, que experimentaram as mencionadas estratégias, atestam que a formação inicial de docentes em química, assim conduzida, favorece tais reflexões. 
Como visto ao longo do texto, a literatura sobre a formação inicial de docentes de química tem discutido de forma incipiente as relações entre os espaços não escolares e tais processos formativos. Buscou-se contribuir para tais discussões, ressaltando as possíveis contribuições de museus/centros de ciências, principalmente no que tange às exposições de ciências, ainda pouco aproveitadas para a educação em química. Trabalhos futuros poderiam investigar as características dos espaços mencionados na seção anterior, visitados durante as experiências de estágio das cinco licenciandas, mapeando seus possíveis aportes para o ensino de conteúdos químicos. Essa é uma lacuna do presente texto que precisa ser sanada, pois a literatura carece de trabalhos que descrevam e analisem, criteriosamente, as contribuições de diversos espaços não escolares brasileiros para o ensino de química. Novas pesquisas poderiam averiguar também se, em outras IES, o processo formativo docente apresentaria sinais de apropriação dos preceitos da racionalidade crítica, no uso das quatro estratégias aqui propostas.

Ainda, é preciso reconhecer outro limite deste trabalho. A apresentação e operacionalização das quatro estratégias, assim como sua ilustração na forma dos diagramas das Figuras 2 a 5, privilegiou percursos lineares, atravessando de forma sucessiva diferentes modalidades do fenômeno educacional. Essa linearidade pode ser desafiada em novos contextos, concebendo-se experiências como, por exemplo, a presença concomitante, dos professores em formação, em espaços escolares e não escolares. Nesse sentido, os formadores de professores, nas diversas IES do país, devem se sentir encorajados a elaborar (e a divulgar) outros itinerários, arranjos e estratégias para além das quatro propostas aqui apresentadas.

A tarefa de educar, tradicionalmente relegada à escola, hoje aparece cada vez mais compartilhada com outros espaços educativos. A formação docente não pode descurar disso, dado que ambientes como museus/centros de ciências estão mais e mais presentes no cotidiano do cidadão brasileiro. Apesar da repartição das horas de estágio entre espaços escolares e não escolares, as experiências com as quatro estratégias propostas não repercutiram na maior valorização dos museus/centros de ciências em detrimento da escola. Pelo contrário, auxiliaram na identificação das especificidades dessa instituição - que, mais do nunca, precisa ser compreendida, prestigiada e defendida, não apenas pelos docentes em formação e em atividade, mas por toda a sociedade civil. Afinal, o espaço escolar ainda é o ambiente de excelência para a socialização dos educandos nas conquistas historicamente elaboradas pela humanidade, ainda que museus e outras instituições não escolares também possam colaborar para esse fim.

\section{AGRADECIMENTOS}

Às estagiárias que participaram da experiência aqui relatada e a todos os trabalhadores dos espaços escolares e não escolares que possibilitaram as visitas de campo.

A. C. Kasseboehmer agradece à Fapesp (Processo nº 2018/20145-7 e Processo no 2017/10118-0) pelo financiamento.

\section{REFERÊNCIAS}

1. Brasil; Lei n. 9.394/1996 - Diretrizes e bases da educação nacional, Brasília, 1996.

2. Nóvoa, A.; Os professores e a sua formação, Dom Quixote: Lisboa, 1992; Schön, D. A.; The reflective practitioner: how professionals think in action, Basic Books: New York, 1983; Schön, D. A.; Educando o profissional reflexivo: um novo design para o ensino e a aprendizagem; Costa, R. C., trad.; Artmed: Porto Alegre, 2000.

3. Brasil; Referenciais para formação de professores. MEC/SEF: Brasília, 1999.
4. Brasil; Resolução CNE/CP n. 1/2002 - Institui Diretrizes Curriculares Nacionais para a Formação de Professores da Educação Básica, em nível superior, curso de licenciatura, de graduação plena, Brasília, 2002.

5. Brasil; Resolução CNE/CP n. 2/2002 - Institui a duração e a carga horária dos cursos de licenciatura, de graduação plena, de formação de professores da Educação Básica em nível superior, Brasília, 2002.

6. Brasil; Resolução CNE/CP n. 2/2004 - Adia o prazo previsto no art. $15 \mathrm{da}$ Resolução CNE/CP 1/2002, que institui Diretrizes Curriculares Nacionais para a Formação de Professores da Educação Básica, em nível superior, curso de licenciatura, de graduação plena, Brasília, 2004.

7. Brasil; Lei n. 13.005/2014 - Aprova o Plano Nacional de Educação PNE e dá outras providências, Brasília, 2014.

8. Baibich-Faria, T. M.; Avaliação (Campinas) 2009, 14, 727.

9. Brasil; Decreto n. 7.219/2010 - Dispõe sobre o Programa Institucional de Bolsa de Iniciação à Docência - PIBID e dá outras providências, Brasília, 2010.

10. Brasil; Resolução CNE/CP n. 2/2015 - Define as Diretrizes Curriculares Nacionais para a formação inicial em nível superior (cursos de licenciatura, cursos de formação pedagógica para graduados e cursos de segunda licenciatura) e para a formação continuada, Brasília, 2015.

11. Brasil; Portaria CAPES n. 38/2018 - Institui o Programa de Residência Pedagógica, Brasília, 2018.

12. Contreras, J.; A autonomia de professores; Valenzuela, S. T., trad.; Cortez: São Paulo, 2002; Zeichner, K. M.; A formação reflexiva de professores: idéias e práticas; Teixeira, A. J. C., Carvalho, M. J., Nóvoa, M., trads.; Educa: Lisboa, 1993; Zeichner, K. M.; Em A pesquisa na formação e no trabalho docente; Pereira, J. E. D.; Zeichner, K. M., eds.; $2^{\mathrm{a}}$ ed., Autêntica: Belo Horizonte, 2008, cap. 3.

13. Ferreira, L. H.; Kasseboehmer, A. C.; Formação inicial de professores de química: a instituição formadora (re)pensando sua função social. Pedro e João: São Carlos, 2012.

14. Duarte, N.; Em Arte, conhecimento e paixão na formação humana: sete ensaios de pedagogia histórico-crítica; Duarte, N.; Fonte, S. S. D., eds.; Autores Associados: Campinas, 2010, cap. 1; Facci, M. G. D.; Valorização ou esvaziamento do trabalho do professor?: um estudo crítico-comparativo da teoria do professor reflexivo, do construtivismo e da psicologia vigotskiana. Autores Associados: Campinas, 2004; Marsiglia, A. C. G., ed.; Pedagogia histórico-crítica: 30 anos. Autores Associados: Campinas, 2011; Martins, L. M.; A formação social da personalidade do professor: um enfoque vigotskiano, $2^{\mathrm{a}}$ ed., Autores Associados: Campinas, 2015; Martins, L. M.; Duarte, N., eds.; Formação de professores: limites contemporâneos e alternativas necessárias. Unesp/Cultura Acadêmica: São Paulo, 2010.

15. Gaspar, A.; Tese de Doutorado, Universidade de São Paulo, Brasil, 1993.

16. McManus, P.; Stud. Sci. Educ. 1992, 20, 157.

17. Cazelli, S.; Marandino, M.; Studart, D.; Em Educação e museu: a construção social do caráter educativo dos museus de ciências; Gouvêa, G.; Marandino, M.; Leal, M. C., eds.; Access/Faperj: Rio de Janeiro, 2003, cap. 4.

18. Gaspar, A.; Tese de Livre Docência, Universidade Estadual Paulista, 2006; Valente, M. E. A.; Marandino, M.; Museum Education and New Museology 2003, 17, 30.

19. Marandino M.; Silveira, R. V. M.; Chelini, M. J.; Fernandes, A. B.; Rachid, V.; Martins, L. C.; Lourenço, M. F.; Fernandes, J. A.; Florentino, H. A.; Anais do $4^{\circ}$ Encontro Nacional de Pesquisa em Educação em Ciências, Bauru, Brasil, 2003.

20. Dib, C. Z.; Am. Inst. Phys. Conf. Proc. 1988, 173, 300; Jacobucci, D. F. C.; Em Extensão 2008, 17, 55; Marques, J. B. V.; Freitas, D.; Educ. Pesqui. 2017, 43, 1087.

21. Educação em museus: a mediação em foco; Marandino, M., ed.; GEENF/FEUSP: São Paulo: 2008; Marandino, M.; Ciênc. Educ. 2017, 23,811 . 
22. Mori, R. C.; Curvelo, A. A. S.; Educ. Pesqui. 2016, 41, 491.

23. Saviani, D.; Pedagogia histórico-crítica: primeiras aproximações, $10^{\mathrm{a}}$ ed., Autores Associados: Campinas, 2008; Saviani, D.; Em Dermeval Saviani e a educação brasileira: o simpósio de Marília, Silva Júnior, C. A.; Severino, A. J., eds.; Cortez: São Paulo, 1994, cap. 18.

24. Saviani, D.; Educação brasileira: estrutura e sistema, $2^{\mathrm{a}}$ ed., Saraiva: São Paulo, 1975; Saviani, D.; Sistema Nacional de Educação e Plano Nacional de Educação. Autores Associados: Campinas, 2014.

25. Sacristán, J. G.; Currículo: uma reflexão sobre a prática; Rosa, E. F. F., trad., $3^{a}$ ed., ArtMed: Porto Alegre, 1998; Silva, T. T.; Documentos de identidade: uma introdução às teorias do currículo, $3^{\mathrm{a}}$ ed., Autêntica: Belo Horizonte, 2011

26. Almeida, C.; Brito, F.; Ferreira, J. R.; Massarani, L.; Amorim, L.; Centros e museus de ciência do Brasil 2015. ABCMC - Associação Brasileira de Centros e Museus de Ciência, Casa da Ciência - Centro Cultural de Ciência e Tecnologia da UFRJ e Museu da Vida - Casa de Oswaldo Cruz/Fiocruz: Rio de Janeiro, 2015.

27. Steola, A. C. S.; Kasseboehmer, A. C.; Quim. Nova 2018, 41, 1072.

28. Palmieri, L. J.; Silva, C. S.; Revista Debates em Ensino de Química 2017, 3, 70 .

29. César, E. T.; Reis, R. C.; Aliane, C. S. M.; Quim. Nova Esc. 2015, 37, 180.

30. Abib, M. L. V. S.; Lamas, A. P. N.; Castro, C.; Lourenço, A. B.; Anais do XVI Encontro Nacional de Didática e Práticas de Ensino, Campinas, Brasil, 2012.

31. Pugliese, A.; Marandino, M.; Anais do X Encontro Nacional de Pesquisa em Educação em Ciências, Águas de Lindóia, Brasil, 2015.

32. Marandino, M.; Em Formação docente em Ciências: memórias e práticas; Selles, S. E., Ferreira, M. S., eds.; EdUFF: Rio de Janeiro, 2003, cap. 5 .

33. Chagas, I.; Revista de Educação 1993, 3, 51.

34. Queiroz, G.; Krapas, S.; Valente, M. E.; David, E.; Damas, E.; Freire, F.; Revista Brasileira de Pesquisa em Educação em Ciências 2002, 2, 77.

35. D.; Ovigli, D. F. B.; Ensino em Re-Vista 2013, 20, 111.

36. Ovigli, D. F. B.; Freitas, D.; Caluzi, J. J. Em Ensino de ciências e matemática, IV: temas de investigação; Pirola, N. A., ed.; Unesp/Cultura Acadêmica: São Paulo, 2010, cap. 5.

37. Tempesta, A. M.; Gomes, L. C.; Investigações em Ensino de Ciências 2017, 22, 78 .

38. Wagensberg, J.; Alambique 2000, 26, 15.

39. Marandino, M.; Rev. Bras. Educ. 2004, 26, 95.

40. Silva, F. C. A.; Almeida, M. M. B.; Santiago, S. B.; Conexões - Ciência e Tecnologia 2015, 9, 105.
41. Souza, G. P.; Pereira, A. I.; Silva, C. M.; Gandra, D. A.; Oliveira, G. P.; Ramos, G. R.; Casela, I.; Fernandes, J. M.; Sena, M. C. C.; Martins, M. R.; Nascimento, M. O.; Fideles, R. A.; Ramos, S. N. C.; Araújo T. D.; Moreira, L. M.; Quim. Nova Esc. 2014, 36, 200.

42. Gonçalves, F. P.; Fernandes, C. S.; Quim. Nova Esc. 2010, 32, 120.

43. Krasilchik, M.; Prática de ensino de Biologia, $4^{\mathrm{a}}$ ed., Edusp: São Paulo, 2012.

44. Bogdan, R. C.; Biklen, S. K.; Investigação qualitativa em educação: uma introdução à teoria e aos métodos; Alvarez, M. J., Santos, S. B., Baptista, T. M., trads.; Porto Editora: Porto, 1994.

45. Vianna, H. M.; Pesquisa em educação: a observação. Plano: Brasília, 2003.

46. Pimenta, S. G.; Lima, M. S. L.; Estágio e docência, $7^{\mathrm{a}}$ ed., Cortez: São Paulo, 2012

47. Zancul, M. C. S.; Ens. Pesqui. Educ. Ciênc. 2009, 11, 87.

48. A expressão "transmissão do conhecimento" não deve ser entendida como um recuo ou concessão à pedagogia tradicional. Estamos trazendo, aqui, a perspectiva da pedagogia histórico-crítica, que considera o processo transmissivo a partir de uma perspectiva histórica e socialmente mediada. Para uma comparação entre os processos de transmissão no marco dessas duas pedagogias, ver: Marinho, B. R.; Gomes, D. R. M.; Em Pedagogia histórico-crítica e psicologia histórico-cultural: a defesa do conhecimento na educação das novas gerações; Marinho, B. R., Peternella, A., eds.; Paço Editorial: Jundiaí, 2018, cap. 1.

49. Barro, M. R.; Baffa, A.; Queiroz, S. L.; Quim. Nova Esc. 2016, 36, 4.

50. Barbosa, J. G.; Hess, R.; O diário de pesquisa. LiberLivro: Brasília, 2010.

51. Bardin, L.; Análise de conteúdo; Reto, L. A., Pinheiro, A., trads.; Edições 70: São Paulo, 2016.

52. Camargo, A. J.; Dlugoviet, T. L.; Wisniewski, G.; Anais do VI Encontro Nacional das Licenciaturas e X Seminário Institucional PIBID/PUCPR, Curitiba, Brasil, 2016; Maruyama, J. A.; Silva, C. S.; Oliveira, L. A. A.; Marques, C. M. P.; Anais do XVI Encontro Nacional de Ensino de Química e X Encontro de Educação Química da Bahia, Salvador, Brasil, 2012; Ribeiro, M. H. S.; Ramos, E. C. S. S.; Carvalho, A. C.; Cavalcante, K. S. B.; Brandão, C. M.; Anais do XVIII Encontro Nacional de Ensino de Química, Florianópolis, Brasil, 2016.

53. Pereira, R. B.; Pinto Neto, P. C.; Leitura: Teoria \& Prática 2015, 33, 49.

54. Milanesi, L.; O que é Biblioteca, $2^{\mathrm{a}}$ ed., Brasiliense: São Paulo, 1984.

55. Zabala, A.; A prática educativa: como ensinar; Rosa, E. F. F., trad.; ArtMed: Porto Alegre, 1998.

56. O papel da pesquisa na formação e na prática dos professores; André, M., ed.; 12 ed., Papirus: Campinas, 2012; Ghedin, E.; Oliveira, E. S.; Almeida, W. A.; Estágio com pesquisa. Cortez: São Paulo, 2015. 